\title{
Water Vapor and Ozone Variations in the Tropical Tropopause Layer during the Central Equatorial Pacific Experiment Campaign
}

\author{
Kazunari KOISHI and Masato SHIOTANI \\ Research Institute for Sustainable Humanosphere, Kyoto University, Kyoto, Japan \\ (Manuscript received 3 March 2011, in final form 2 March 2012)
}

\begin{abstract}
Water vapor and ozone profiles in the tropical tropopause layer (TTL) are investigated using measurements from balloon-borne frost-point hygrometers and ozone sensors during the Central Equatorial Pacific Experiment campaign. Variations in water vapor, ozone, and temperature are described during soundings taken over a period of two weeks and over a distance of approximately $2,700 \mathrm{~km}$ along the equator. These observations indicate that the first and latter halves of the campaign period are characterized as cold and warm phases near the cold point tropopause, respectively. Stationary and eastward-traveling components equally contributed to these temperature anomalies. During the transition between the two phases, the ozone increased around 350-400 K, with the maxima around the $360 \mathrm{~K}$ isentrope. The water vapor simultaneously increased and decreased around the 360-400 K and 350-360 K isentropes, respectively. Simultaneous increases in ozone and water vapor around 360-400 K with a reduction in the vertical gradients suggest the possibility of turbulent mixing associated with a large-scale wave structure. The enhancement of vertical shear of zonal wind during the transition between the two phases also supports this idea. The decrease in water vapor around the 350-360 K isentropes could be understood as a result of saturation on the isentropic surface. This study shows the importance of observing variations in isentropic coordinates, rather than altitude coordinates, around the TTL in order to make a quantitative argument concerning mixing and dehydration when a large-amplitude disturbance exists.
\end{abstract}

\section{Introduction}

The tropical tropopause plays an important role in imprinting the characteristics of air entering the stratosphere from the troposphere (Brewer 1949; Holton et al. 1995). The vertical structures of trace gases, such as water vapor and ozone, across this level are described by the characteristic change from a tropospheric turbulent layer to a stratospheric stable layer. Owing to this property, this altitude range is called the tropical tropopause layer (TTL). For more than a decade, many researchers have improved their understanding of the dynamics, radiation, and transport in the TTL using a wide variety

Corresponding author: Kazunari Koishi, Research Institute for Sustainable Humanosphere, Kyoto University, Gokasho, Uji, Kyoto 611-0011, Japan.

E-mail: koishi@rish.kyoto-u.ac.jp

(c)2012, Meteorological Society of Japan of data from recent satellite measurements, field campaigns, and model simulations (e.g., Fueglistaler et al. 2009, and references therein).

Low temperatures, including large-scale dynamics around the tropical tropopause, are important for dryness in the stratosphere. Several mechanisms have been proposed by many researchers (e.g., Holton and Gettelman 2001; Hatsushika and Yamazaki 2003; Jensen and Pfister 2004; Fueglistaler et al. 2005; Fueglistaler and Haynes 2005). The key concept is that minimum temperatures along trajectories limit the amount of water vapor in the stratosphere. On the other hand, several explanations have been proposed for the hydration mechanism in the TTL, such as those associated with aerosol variations (Sherwood 2002; Notholt et al. 2005) and overshooting convection (e.g., Chaboureau et al. 2007; Corti et al. 2008). An understanding of the relationship between these water vapor dehydration and hydration mechanisms is one of the most important requirements for clarifying the processes in the TTL. 
Many researchers have described vertically and horizontally propagating equatorial waves in the equatorial atmosphere (e.g., Wheeler et al. 2000; Straub and Kiladis 2002; Suzuki et al. 2010a). Boehm and Verlinde (2000) and Fujiwara et al. (2001) noted that equatorial waves could be important for modulating the amount of water vapor in the TTL. Because temperature fluctuations caused by equatorial waves near the cold point tropopause (CPT) are quite large (e.g., Tsuda et al. 1994), air parcels should encounter temperatures below the average value.

Equatorial waves play another important role as demonstrated by observational evidence, suggesting vertical mixing of air parcels in association with Kelvin wave breaking (Fujiwara et al. 1998; Fujiwara et al. 2003). In the tropical latitudes, a steep increase in the ozone mixing ratio above approximately $14 \mathrm{~km}$ (a few kilometers below the CPT) has been observed. Using ozonesonde data, which are useful for analyzing the transport history of air parcels in the TTL, Folkins et al. (1999) proposed that this steep increase is due to the suppression of vertical mixing associated with convective transport in the TTL. Very recently, Flannaghan and Fueglistaler (2011) used data from the European Centre for Medium-Range Weather Forecasts (ECMWF) interim reanalysis project to suggest that the TTL may be affected by mixing from shear-flow instability associated with Kelvin waves.

This paper focuses on a series of vertical water vapor and ozone profiles obtained from the Central Equatorial Pacific Experiment (CEPEX) campaign in March 1993. In this study, we complement earlier analyses of those measurements (Vömel et al. 1995; Kley et al. 1997) with an analysis that focuses on the equatorial wave structure during the observation period and its relation to the water vapor and ozone distributions. This study explores variations in water vapor and ozone in association with the background meteorological fields and wave properties. The water vapor and ozone mixing ratios in isentropic coordinates are analyzed, assuming adiabatic motion. The non-conservative processes involving water vapor and ozone seen in this campaign period will be investigated in terms of possible irreversible mixing.

The observation datasets are described in Section 2. The vertical water vapor and ozone profiles and the large-scale dynamical fields are described in Section 3. The observed differences between the isentropic and altitude coordinates, and the possible causes of variations in water vapor and ozone associated with the dynamical structure of large-scale waves are discussed in Section 4. Conclusions are presented in Section 5.

\section{Data}

Balloon-borne measurements obtained during the CEPEX campaign were used in this analysis. These soundings were conducted in the central Pacific in March 1993, along a cruise route mostly at $2^{\circ} \mathrm{S}$, and on Christmas Island at $157.12^{\circ} \mathrm{W}, 1.30^{\circ} \mathrm{N}$ (Vömel et al. 1995). This experiment was designed to capture vertical profiles for water vapor and ozone from the middle troposphere to the lower stratosphere in both the convectively active and suppressed regions in the central Pacific Ocean. As will be described in Section 3, we used data ranges from $178.46^{\circ} \mathrm{E}, 2.00^{\circ} \mathrm{S}$ to $157.12^{\circ} \mathrm{W}$, $1.30^{\circ} \mathrm{N}$, covering a distance of approximately $2700 \mathrm{~km}$, for our primary analysis. The corresponding longitudinal observation points are indicated by stars in Fig. 3 . The observation period is approximately two weeks.

Water vapor and ozone were measured by a frostpoint hygrometer (FPH) and an electrochemical concentration cell (ECC) sensor, respectively (Vömel et al. 1995; Kley et al. 1997). For analysis in subsequent sections, the temperature, pressure, geopotential height, potential temperature, relative humidity with respect to ice, saturation mixing ratio, water vapor mixing ratio, and ozone mixing ratio are used. The water vapor mixing ratio was obtained from the frost point using the Goff-Gratch equation. These data are all interpolated on an altitude grid with a $250 \mathrm{~m}$ interval. Vömel and Diaz (2010) recently pointed out that extremely low ozone mixing ratios in the upper troposphere may be an artifact. We do not apply their suggested correction because the exact values of very low ozone concentrations are not important in this study.

We use quarterly daily temperature and zonal wind data from the ECMWF 40-year reanalysis (ERA-40) and daily outgoing long-wave radiation (OLR) data from the National Oceanic and Atmospheric Administration (NOAA) in order to capture the features of largescale fields.

\section{Descriptions of water vapor, ozone, and temper- ature}

\subsection{Vertical distributions of water vapor and ozone}

Figure 1 shows vertical profiles of (a) the water vapor mixing ratio and (b) the ozone mixing ratio from March 7-26, 1993 from the upper troposphere to the lower stratosphere, with an offset from earlier to later profiles (far right). The spatial and time lags of these soundings were up to $200 \mathrm{~km}$ and 2.5 days respectively, as we will see in Fig. 3. Profiles 1-8 correspond to cruise observations, and profiles 9 and higher are from observations on Christmas Island. Figure 1a shows that the water 
a)

Water Vapor Mixing Ratio

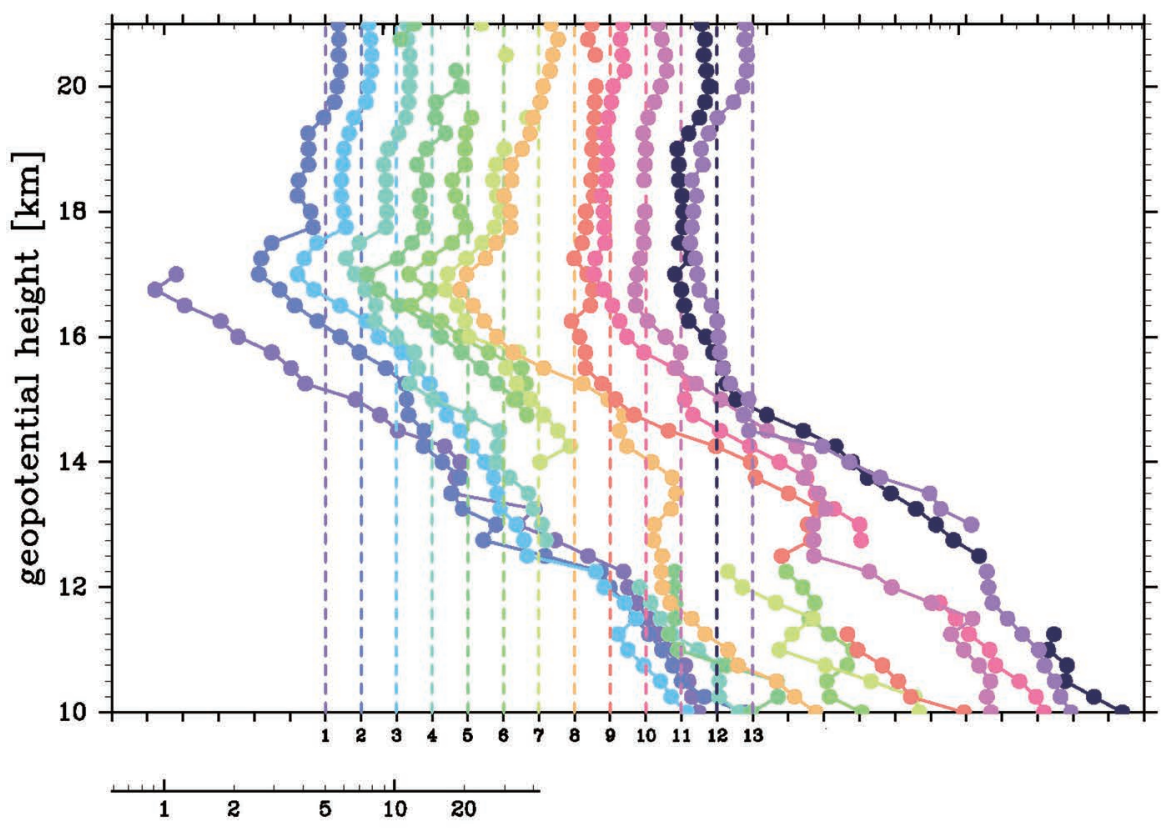

b) Ozone Mixing Ratio

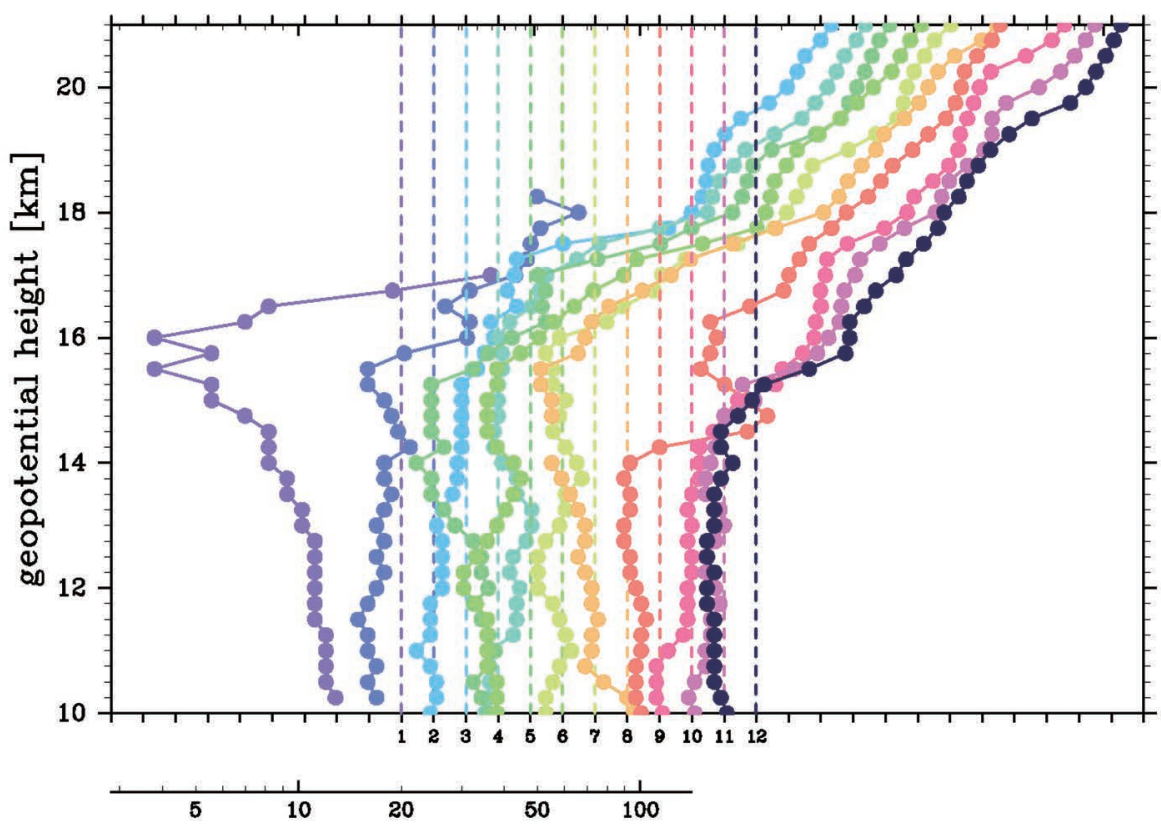

Fig. 1. Vertical profiles of (a) water vapor and (b) ozone mixing ratios. Profiles obtained from CEPEX using 13 FPH and 12 ECC ozonesonde measurements are shown on a logarithmic scale. Each color denotes one sounding. Later profiles are shifted to the right. Dashed lines indicate reference axes of $5 \mathrm{ppmv}$ for water vapor and $20 \mathrm{ppbv}$ for ozone. 
a) Vickers Cruise day $7-17$ Mar.1993

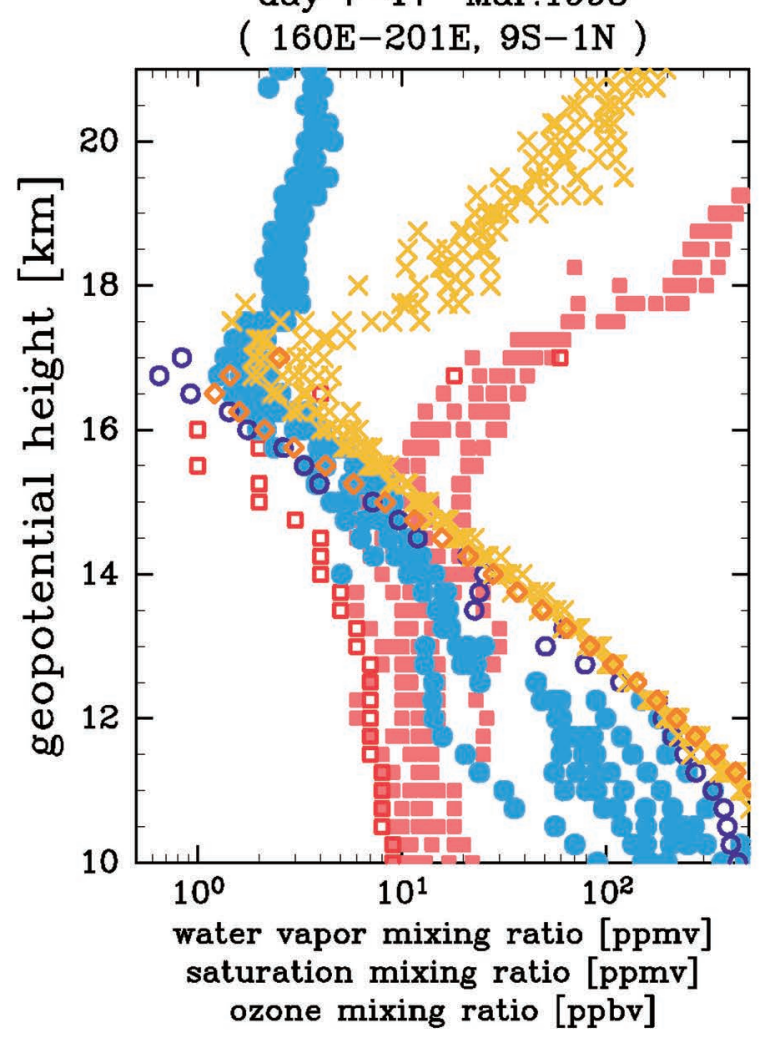

b) Christmas Is. day 20-26 Mar.1993 ( 203E-203E, 2S-2N )

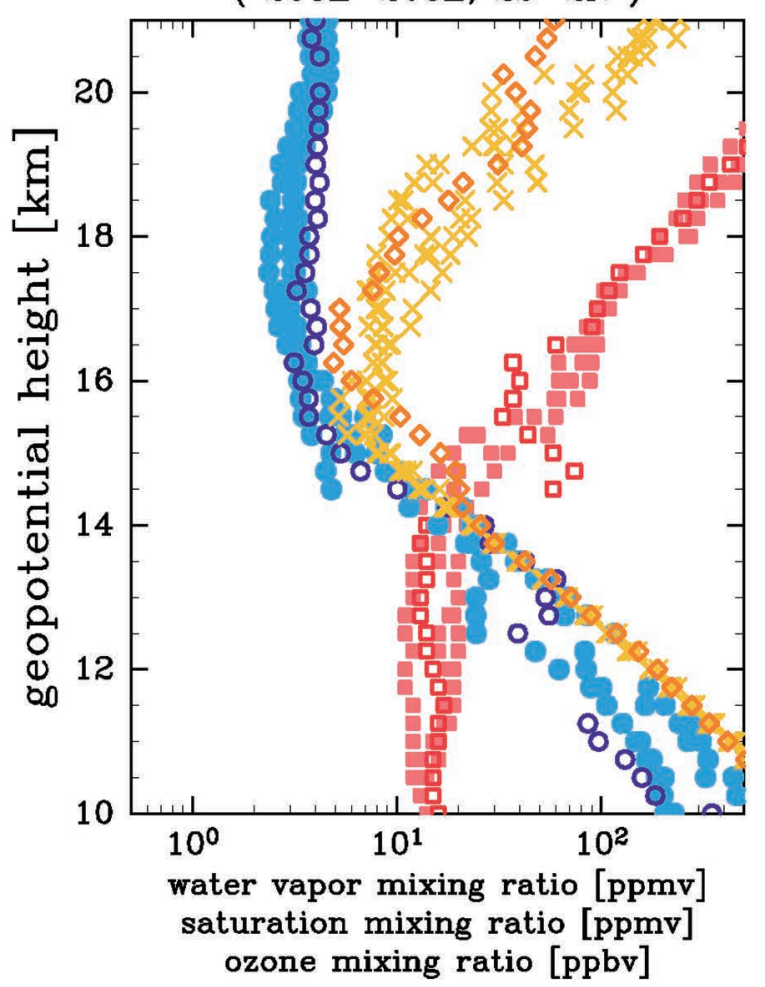

Fig. 2. Water vapor (blue), saturation water vapor (yellow), and ozone (red) mixing ratio profiles: period from (a) days 7 to 17 and (b) days 20 to 26. Corresponding profile numbers are from 1 to 8 and from 9 to 13, respectively. Profiles 1 and 9 are indicated by open symbols with darker colors.

vapor mixing ratios of profiles $1-8$ decrease with an increase in altitude up to $17 \mathrm{~km}$, and those of profiles 9-13 are roughly constant above $15 \mathrm{~km}$. Consequently, the amount of water vapor around the tropopause is much lower in the earlier period than in the later period, as we will see in Fig. 2. Figure 1b shows that the ozone profiles in the earlier period are almost constant up to the tropopause level $(\sim 16 \mathrm{~km})$, but those in the later period increase gradually in the upper troposphere (14-16 km), although some profiles are exceptional, such as profiles 1 and 9. As a result, the amount of ozone around the tropopause is much lower in the earlier period than in the later period.

To clarify the characteristics of water vapor and ozone near the CPT, Fig. 2 shows the profiles of water vapor mixing ratios (blue), saturation mixing ratios (yellow) calculated from the ambient temperature, and ozone mixing ratios (red) in two different locations and periods. Figure $2 \mathrm{a}$ shows profiles $1-8$, obtained during the cruise from March 7 to March 17; and Fig. 2b shows profiles 9-13, observed on Christmas Island from March 20 to March 26.

In the saturation mixing ratio profiles, minima around $17 \mathrm{~km}$ are seen in Fig. 2a, whereas in Fig. 2b, minima are less marked and appear around $15-17 \mathrm{~km}$. These differences are attributed to the vertical temperature structures, which correspond to the extremely cold tropopause with a sharp minimum and the relatively warm tropopause with a gradual lapse rate, respectively. As we will see in Figs. 3 and 8, the peak-to-peak temperature variability at $100 \mathrm{hPa}$ is approximately $10 \mathrm{~K}$, which may be produced by a combination of an almost stationary cold area in the central Pacific and an eastward-moving atmospheric system, probably due to a Kelvin wave. In addition, we see clearly in Fig. $5 c$ that the signs of temperature anomalies around the 

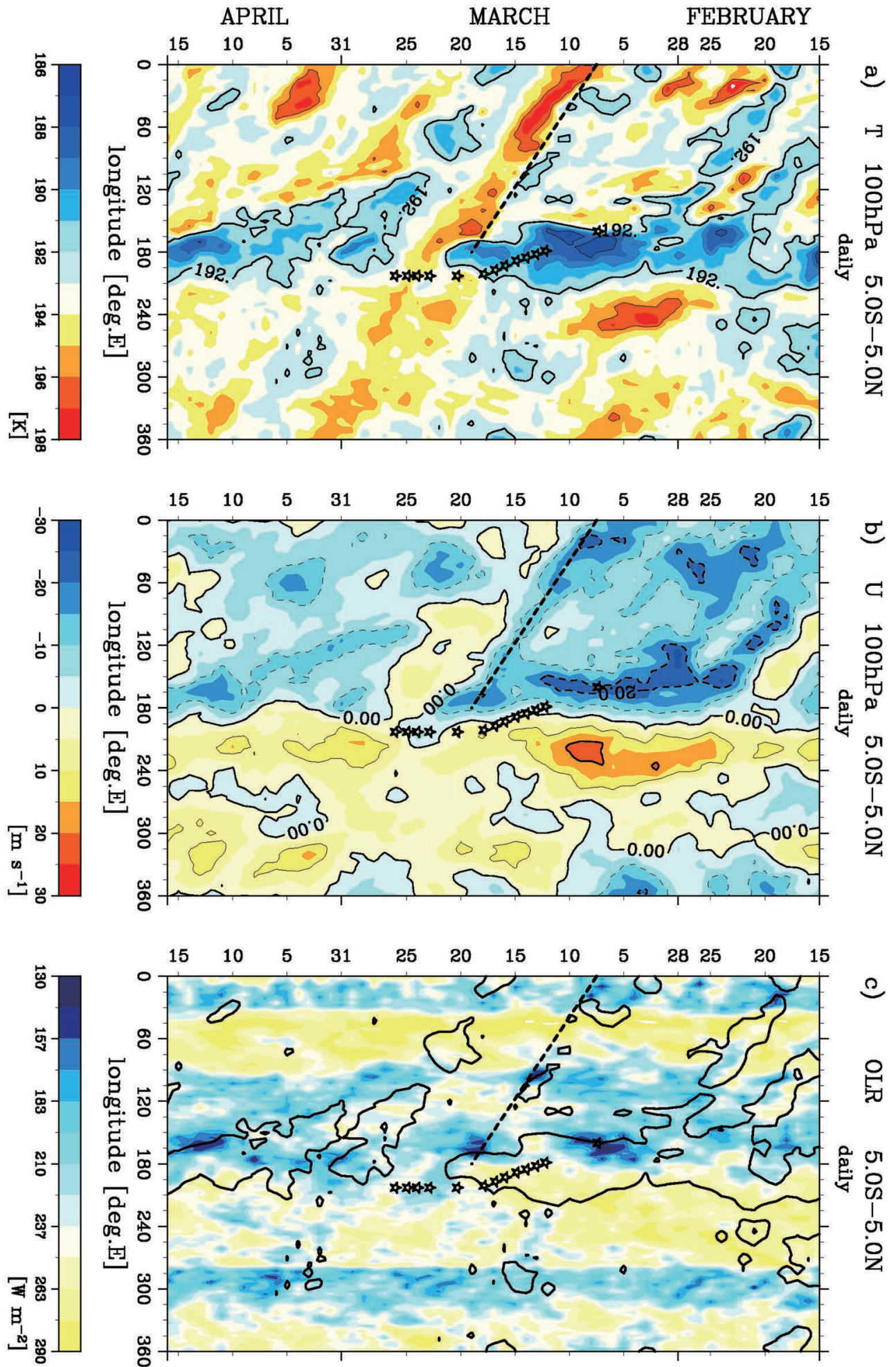

Fig. 3. Longitude-time sections averaged over $5^{\circ} \mathrm{S}-5^{\circ} \mathrm{N}$. (a) $100 \mathrm{hPa}$ temperature and (b) $100 \mathrm{hPa}$ zonal wind from ERA-40, and (c) OLR field from NOAA satellites. Stars indicate observed locations and times. Thick dashed lines indicate approximate phase lines along the eastward traveling disturbance. 

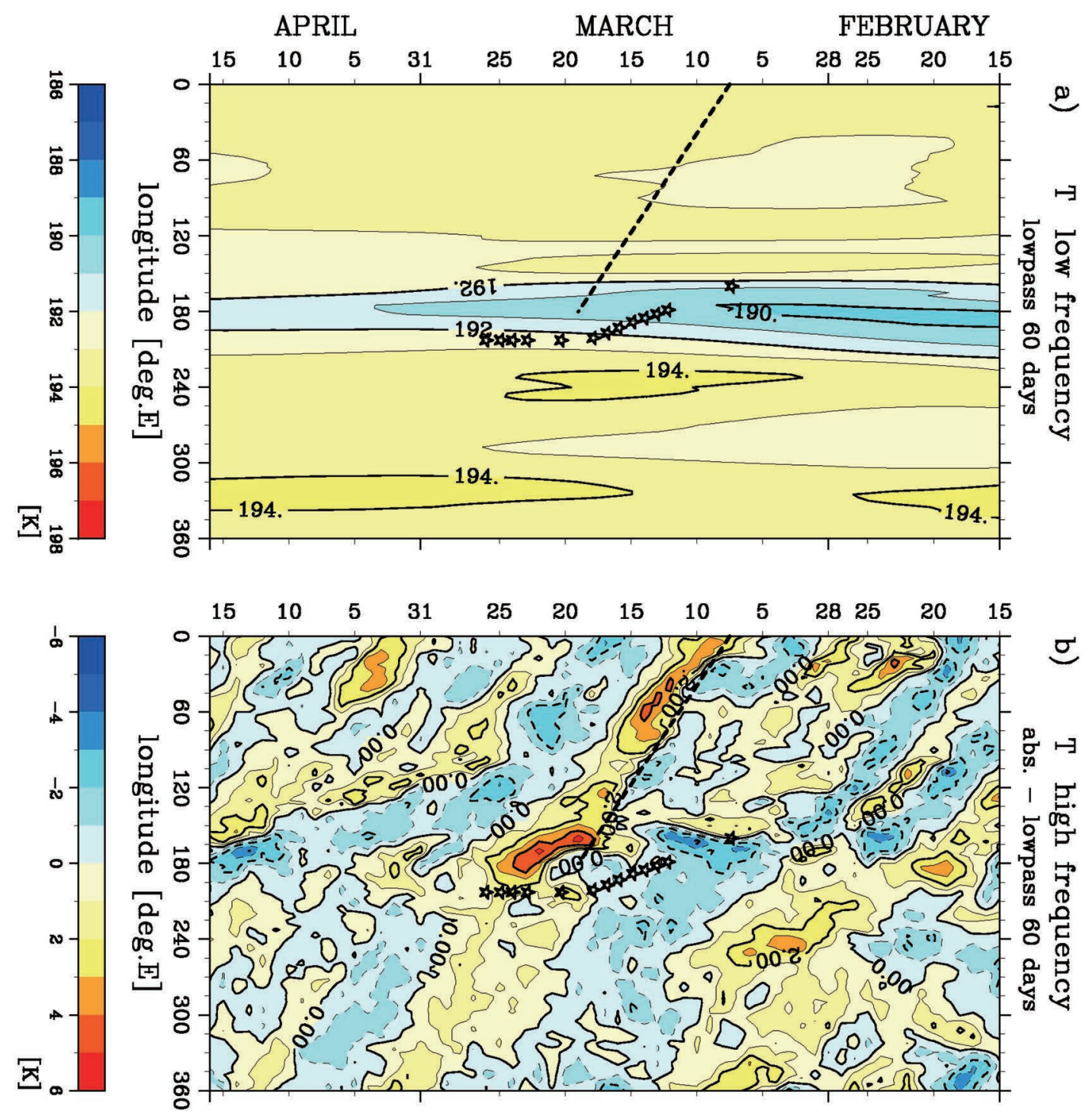

Fig. 4. Longitude-time sections of $100 \mathrm{hPa}$ temperature from ERA-40 averaged over $5^{\circ} \mathrm{S}-5^{\circ} \mathrm{N}$. (a) Low frequency component and (b) high frequency component. Observed locations, times, and phase lines of the eastward traveling disturbance are the same as in Fig. 3.

tropopause are the opposite of those in the upper troposphere, suggesting variability in the structure of the TTL.

The water vapor and saturation mixing ratio profiles are almost saturated from 15 to $17 \mathrm{~km}$ in Fig. 2a, and from 13 to $15 \mathrm{~km}$ in Fig. 2b, if we define saturation using the Clausius-Clapeyron relation. In these altitude ranges, cirrus clouds may exist at different heights, although they were not observed directly during this period. The ozone profiles are also clearly different in the two periods. The mixing ratios around the tropopause are higher in Fig. 2b than in Fig. 2a. In these two periods, it seems that the saturation, water vapor, and ozone mixing ratios could be controlled by a common mechanism near the CPT because the two periods show distinctive changes in the TTL.

In Fig. 2, the exceptional profiles, 1 and 9, are plotted by open symbols. For profile 1, observed on March 7 , the water vapor mixing ratios show considerably low values and are below 1 ppmv above $16 \mathrm{~km}$ in Fig. 2a. 
Vömel et al. (1995) interpreted this profile as a consequence of dehydration associated with deep convection. These water vapor mixing ratios correspond to low saturation mixing ratios due to extremely low temperatures. For profile 9, observed on March 20 on Christmas Island, the ozone distribution has a local maximum with a wavy variation around $15 \mathrm{~km}$, corresponding to warm anomalies around this altitude. In the following discussion, these two profiles will be excluded from the averages over each of the two periods.

\subsection{Large-scale temperature disturbance near the tropopause}

To understand the tracer profile differences between the two periods, Fig. 3 describes the longitude-time distributions of (a) temperature and (b) zonal wind at $100 \mathrm{hPa}$ from the ERA-40 data, and (c) OLR data from NOAA averaged over $5^{\circ} \mathrm{S}-5^{\circ} \mathrm{N}$ for 60 days from February 15 to April 16, 1993. Isothermal lines at $192 \mathrm{~K}$ are drawn in Figs. 3a and 3c. The locations and times of soundings are indicated by stars. During this period, an almost stationary cold area existed around the date line with eastward traveling disturbances superimposed (Fig. 3a). Cold regions are usually seen in the divergent area of zonal winds for both the stationary and eastward-traveling components, indicating that a quadrature phase relationship exists between the temperature and the zonal wind (Fig. 3b). In addition, low temperatures appear on the eastern side of the largescale active convection indicated by low OLR values (Fig. 3c). For the traveling component in particular, it is suggested that a Kelvin wave response to convective heating exists in the troposphere (e.g., Wheeler et al. 2000; Straub and Kiladis 2002).

For the observational period denoted by stars in Fig. 3 , the characteristic change around the tropopause seen in Fig. 2 is interpreted as variation in the temperature field from cold to warm anomalies. During this period, cold anomalies appear mostly in the central Pacific with some intermissions due to warm anomalies traveling eastward with a phase speed of approximately $20 \mathrm{~m} \mathrm{~s}^{-1}$. To denote the eastward-propagating signature, a supplemental line is plotted in Fig. 3. Along this line, active convective regions appear with lower OLR, easterly winds, and nodes of cold and warm anomalies. The first half of the CEPEX observation period lies in the almost stationary cold anomalies, and the latter half on Christmas Island lies in the eastward traveling warm anomalies. In other words, this observation period can be characterized as a combination of the almost stationary and eastward-traveling components. The variations in the waves are further explained below.
Figures $4 \mathrm{a}$ and $4 \mathrm{~b}$ show longitude-time sections of the $100 \mathrm{hPa}$ temperature averaged over the equator $\left(5^{\circ} \mathrm{S}-5^{\circ} \mathrm{N}\right)$ for the low frequency and high frequency components, respectively. The low frequency component is calculated by a 60-day low-pass filter (Duchon 1979), and the high frequency is a residual. During this analysis period, almost stationary cold anomalies appear around the date line with lower temperatures in the first and latter halves (Fig. 4a). At the same time, eastward-traveling temperature anomalies exist across the entire globe. The vertical phase structures of the temperature and zonal wind tilt eastward with increasing altitude between the 300 and $50 \mathrm{hPa}$ levels (not shown), clearly suggesting the existence of a Kelvin wave in response to the convective heat source moving eastward (e.g., Wheeler and Kiladis 1999; Wheeler et al. 2000; Suzuki et al. 2010a).

Temperature variations due to the two components tend to work in a similar way except that the first half of the CEPEX period is colder than the latter half. Along the observation points, the variation is approximately 3 $\mathrm{K}$ for the stationary component and approximately $4 \mathrm{~K}$ for the traveling component. Thus, a large fluctuation of approximately $7 \mathrm{~K}$ could be due to an overlapping of the eastward-propagating wave and the stationary structure in the central Pacific near the tropopause.

\section{Characteristics of vertical distributions in alti- tude and isentropic coordinates}

\subsection{Average profiles of water vapor and ozone mixing ratios}

To distinguish between the two periods, the averaged profiles of water vapor and ozone are examined. Because the temperature variation involves the undulation of an isentropic surface, we compare the two averaged profiles in altitude and isentropic coordinates. In Fig. 5 , the profiles of (a) water vapor (circles) and (b) ozone (squares) are plotted in altitude coordinates for the first half of the period (open symbols) and the latter half (solid symbols) as described for Figs. 1 and 2. Hereafter, the first period refers to the cold phase and the latter refers to the warm phase as seen in the CPT temperatures.

For the water vapor minimum around $17 \mathrm{~km}$, the average water vapor mixing ratios in the cold and warm phases are $1.6 \mathrm{ppmv}$ and $2.8 \mathrm{ppmv}$, respectively. Both are less than the typical value of $3.5 \mathrm{ppmv}$ in the stratosphere, implying the possible existence of some kind of dehydration mechanism during this season. The ozone mixing ratios are larger in the warm phase than in the cold phase, suggesting a large contribution from stratospheric ozone-rich air in the warm phase. 

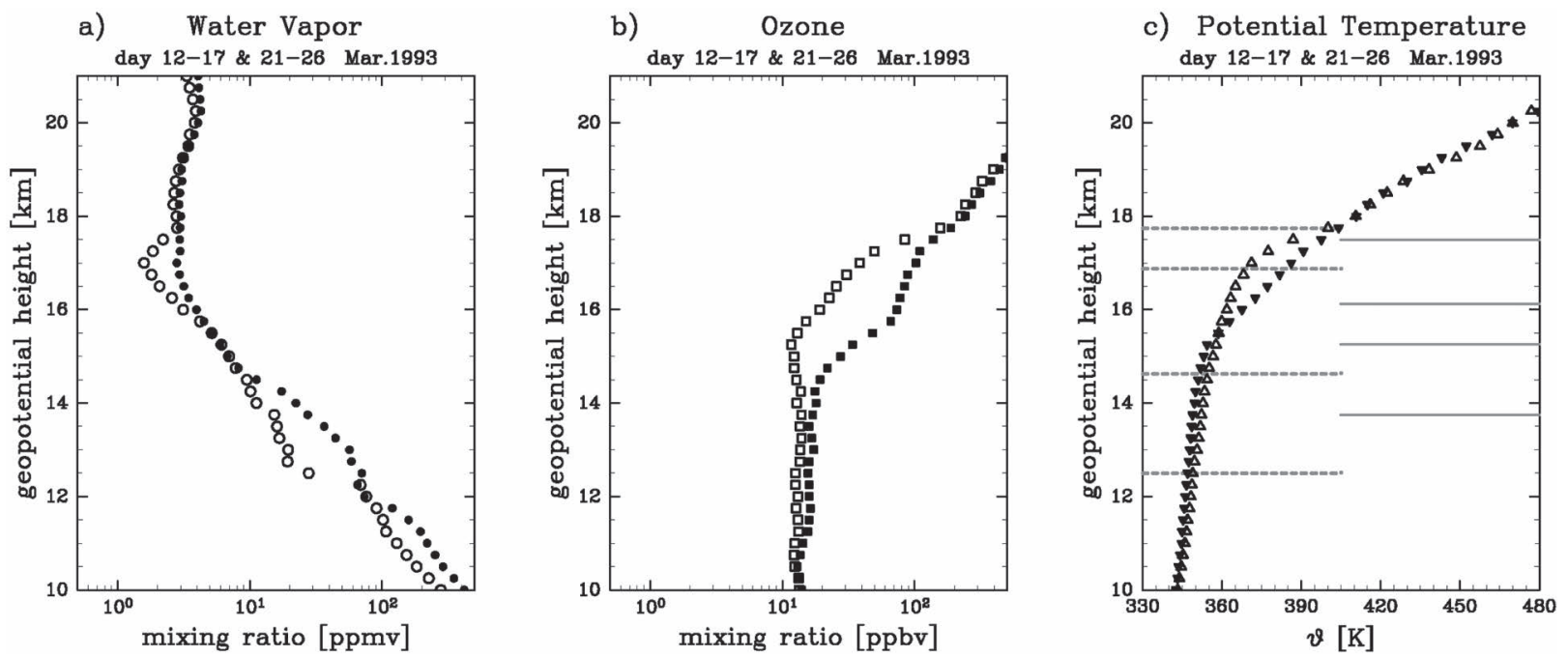

Fig. 5. Averaged profiles in the cold phase (open symbols) and the warm phase (solid symbols) in altitude coordinates. (a) Water vapor mixing ratio, (b) ozone mixing ratio, and (c) potential temperature profiles. Dashed (cold phase) and solid (warm phase) lines in (c) denote selected isentropic surfaces of 350, 355, 370, and $400 \mathrm{~K}$.

a) Water Vapor

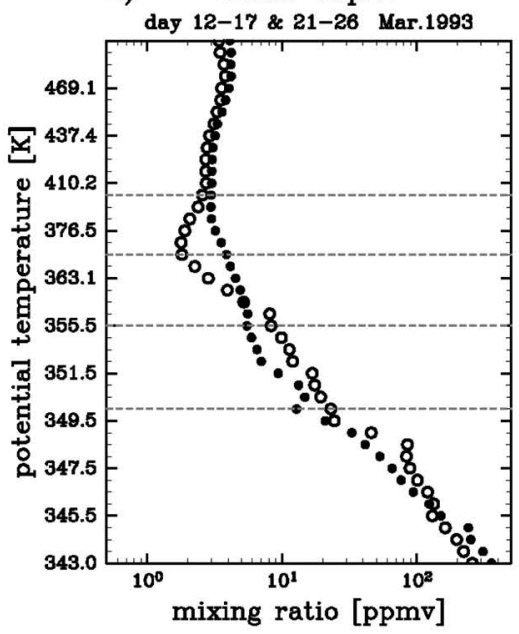

b)

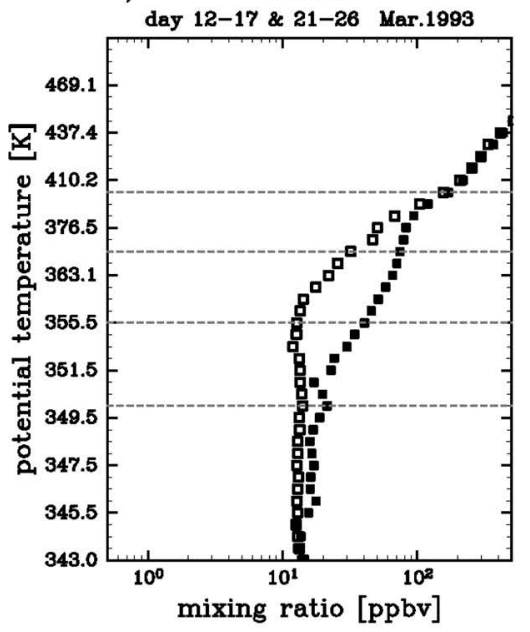

c) Relative Difference
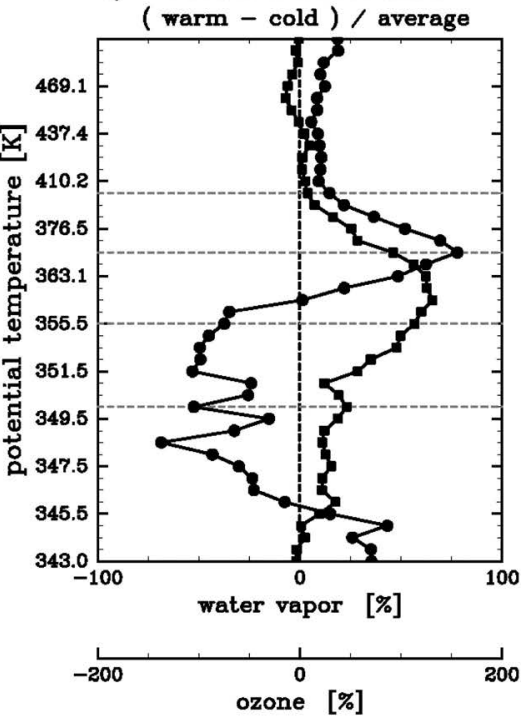

Fig. 6. Averaged profiles in the cold phase (open symbols) and warm phase (solid symbols) in isentropic coordinates. (a) Water vapor mixing ratio and (b) ozone mixing ratio profiles. (c) Water vapor (circles) and ozone (squares) tendencies from the cold to the warm phase represented by relative differences.

Figure 5c shows two averaged potential temperature profiles (triangles) in the cold phase and warm phase. Four isentropic surfaces at $350,355,370$, and $400 \mathrm{~K}$ are indicated by dashed and solid horizontal lines for the cold and warm phases, respectively. The thicknesses between the 350 and $355 \mathrm{~K}$, and between the 355 and $370 \mathrm{~K}$ isentropes, are smaller; and those between 370 and $400 \mathrm{~K}$ are larger in the warm phase than in the cold phase. The difference in the water vapor profiles around $13 \mathrm{~km}$ in Fig. 5a may be related to an ascent of the isen- 
a) U along observation points

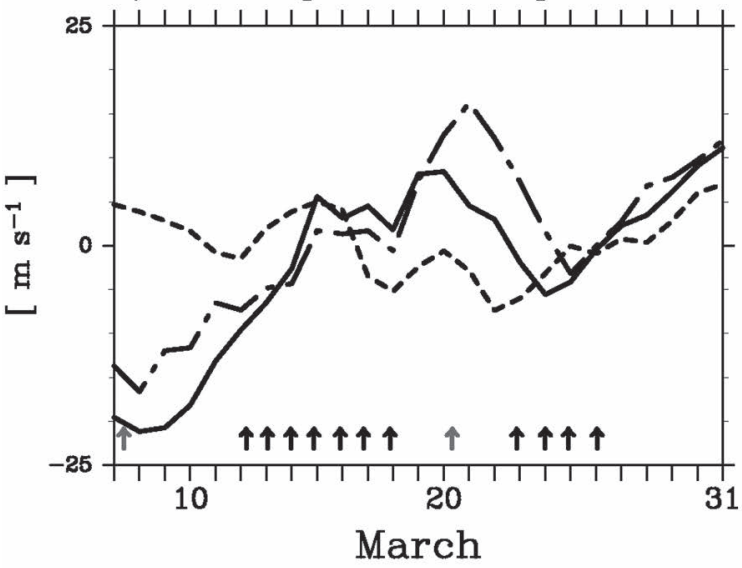

b) U shear along observation points

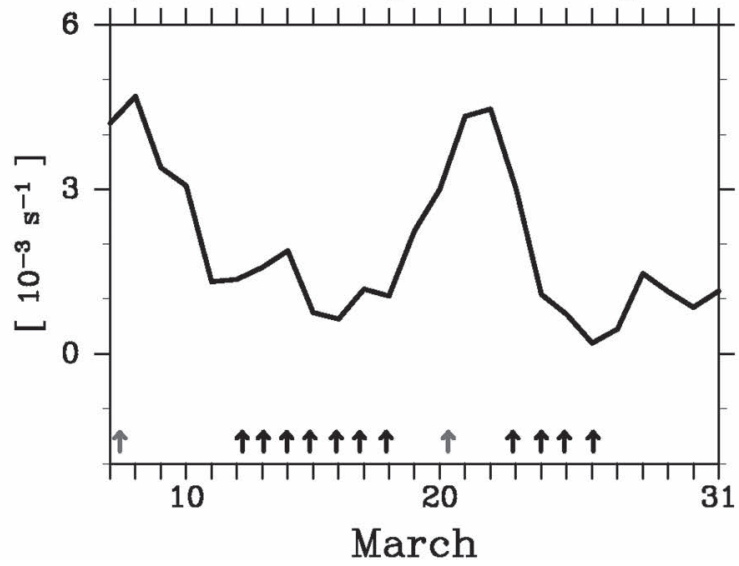

Fig. 7. Zonal wind and vertical shear derived from ERA-40 along observation points. (a) Dashed, solid, and dot-dashed lines represent 70,100 , and $150 \mathrm{hPa}$ zonal winds, respectively. (b) $100 \mathrm{hPa}$ vertical shear. Arrows indicate days observed by CEPEX. Note that averaging procedure excludes the two profiles indicated by gray arrows. See the text for details.

tropic surface. In addition, the difference in the ozone profiles around $16-17 \mathrm{~km}$ in Fig. $5 \mathrm{~b}$ may be related to a descent of the isentropic surface. The association with vertical displacement of the isentropic surfaces suggests that the water vapor and ozone distributions could be affected by perturbations in the large-scale temperature disturbance.

For the equatorial Kelvin wave, the estimated vertical phase velocity is on the order of $10^{-3} \mathrm{~m} \mathrm{~s}^{-1}$ (e.g., Fujiwara and Takahashi 2001), which is much faster than the seasonal-scale vertical velocity, $5 \times 10^{-4} \mathrm{~m} \mathrm{~s}^{-1}$ (e.g., Holton and Gettelman 2001). If the vertical displacement of the isentropic surface is assumed to be due to a Kelvin wave, a vertical ascent or descent of approximately $2 \mathrm{~km}$ is estimated to take approximately a week. Because the vertical motion due to radiative heating is estimated to be lower than the order of $1 \mathrm{~K} \mathrm{day}^{-1}$ (e.g., Corti et al. 2006), adiabatic vertical motion with a time scale of approximately a week is assumed to dominate, particularly when large-amplitude waves exist. To evaluate the changes in water vapor and ozone, the mixing ratios in isentropic coordinates are investigated below.

Figures $6 \mathrm{a}$ and $6 \mathrm{~b}$ show the water vapor and ozone profiles for the two regimes respectively, and Fig. $6 \mathrm{c}$ shows the differences between the two for water vapor (circles) and ozone (squares) in isentropic coordinates. In Fig. 6a, the water vapor mixing ratios in the upper TTL between 360 and $400 \mathrm{~K}$ are lower in the cold phase than in the warm phase, which can also be seen in Fig. 5a. However, the mixing ratios in the lower TTL between 345 and $360 \mathrm{~K}$ are lower in the warm phase than in the cold phase, which is the opposite of the result in Fig. 5a in altitude coordinates. Thus, the water vapor increase seen in altitude coordinates could be a result of the displacement of isentropic surfaces. Note that increases in tracers seen in altitude coordinates include both the contribution from diffusion process and adiabatic advection process. Such temporal differences in water vapor between the two regimes in the cold and warm phases appear in Fig. 6c.

The ozone mixing ratios between 350 and $400 \mathrm{~K}$ in the entire TTL represent higher values in the warm phase than in the cold phase (Fig. 6b); the difference is highest at $360 \mathrm{~K}$ (Fig. 6c). This strongly suggests that the change in the ozone mixing ratio is due to crossisentropic transport rather than adiabatic vertical displacement of air parcels. Irreversible transport, possibly from the stratosphere, is supported by Fujiwara et al. $(1998,2003)$ who described the role of Kelvin waves and their influence on the turbulence. Possible mechanisms for the variations in water vapor and ozone around the height ranges of 360-400 K and 350-360 K (the upper and lower TTL, respectively) are discussed in the next subsections in association with the vertical displacement of isentropic surfaces.

\subsection{Possibility of cross-isentropic transport}

Using water vapor and ozone sonde measurements similar to those used in this study, Fujiwara et al. (2001) demonstrated that increasing water vapor and decreasing ozone appear around the tropopause in the upwarddisplacement phase of a Kelvin wave because the verti- 
a)

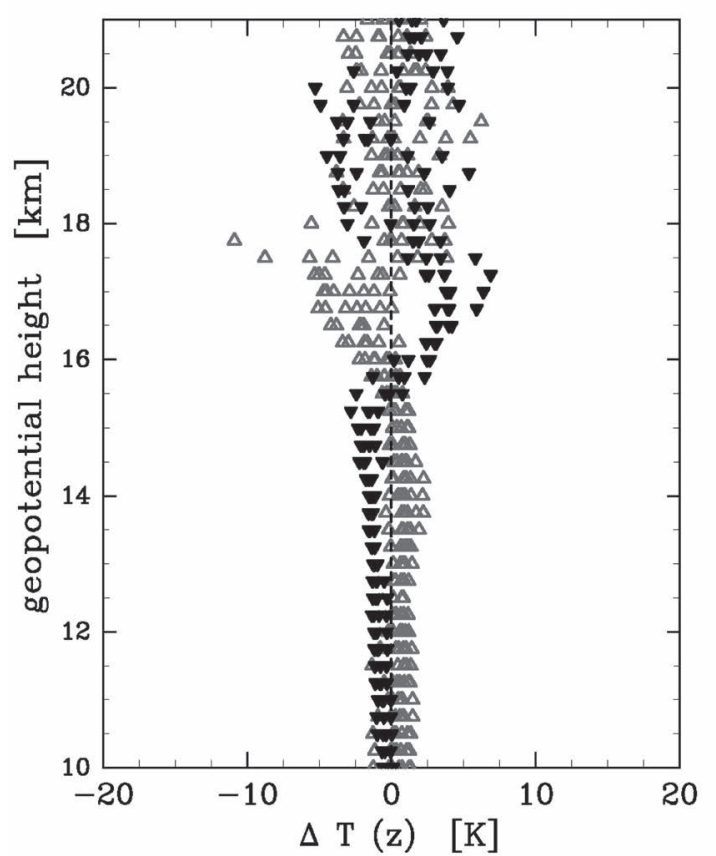

b) Isentropic coordinate

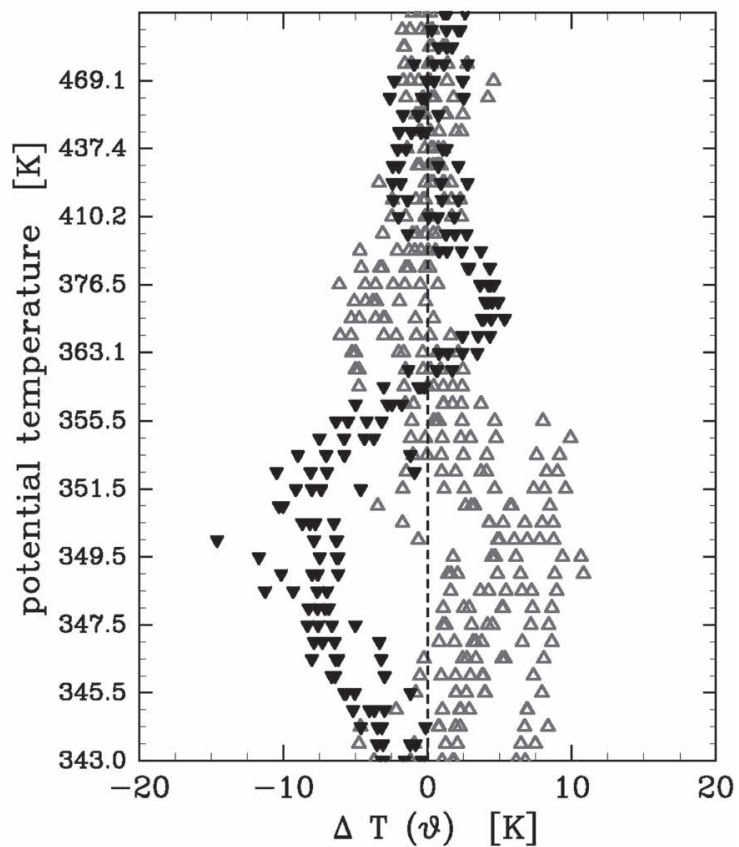

Fig. 8. Vertical structure of the temperature anomaly in the cold phase (open triangles) and warm phase (solid triangles) for the observational period in (a) altitude coordinates and (b) isentropic coordinates.

cal gradient of water vapor is negative, whereas ozone is positive. Figure 6, however, shows low amounts of water vapor and ozone in the cold phase in the upper TTL, and high amounts of water vapor and ozone in the warm phase in the upper TTL, indicating a positive correlation between water vapor and ozone. Moreover, in Figs. $6 \mathrm{a}$ and $6 \mathrm{~b}$, the water vapor and ozone profiles both become smoother with reduced vertical gradients in the warm phase compared with the cold phase, suggesting a possible vertical mixing process due to a Kelvin wave around this height.

Flannaghan and Fueglistaler (2011) recently suggested possible mixing from shear-flow instability due to Kelvin waves in the TTL. Figure 7 shows (a) time series of zonal wind interpolated along the observation points at 70, 100, and $150 \mathrm{hPa}$ from the ERA-40 data, and (b) that of the vertical wind shear calculated from the data at 70 and $150 \mathrm{hPa}$. The wind shear clearly becomes strong during the period between the cold and warm phases; the peak appears just before profile 10, at the beginning of the warm phase. In the analyses of Figs. 5 and 6, we discarded profile 9 because it is highly disturbed. However, that profile would be reasonable if we suppose that it is affected by turbulent mixing from the wind shear.

\subsection{Temperature and water vapor variations in isen- tropic coordinates}

To interpret the change in water vapor in the lower TTL between 345 and $360 \mathrm{~K}$ where the idea of vertical mixing may not be applied to a decrease in water vapor; in this subsection, we discuss quantitatively how temperature disturbances in isentropic coordinates contribute to the saturation mixing ratio of water vapor. First, we examine the temperature variations during the cold and warm phases in altitude and isentropic coordinates.

Figures $8 \mathrm{a}$ and $8 \mathrm{~b}$ show the temperature anomalies over the observational period in altitude $(\Delta T(z))$ and isentropic $(\Delta T(\theta))$ coordinates, respectively. Open and solid triangles represent temperature anomalies in the cold and warm phases, respectively. The mean value was calculated from the average over all available profiles. In the stratosphere above $400 \mathrm{~K}, \Delta T(\theta)$ is smaller than $\Delta T(z)$. In the TTL below $370 \mathrm{~K}, \Delta T(\theta)$ is larger than $\Delta T(z)$; the largest anomaly seen in $\Delta T(\theta)$ is approximately $10 \mathrm{~K}$ at approximately $350 \mathrm{~K}$. The reason is that strong stability in the stratosphere prevents ver- 
Table 1. Relationship between temperature anomaly in isentropic coordinates and relative difference in saturation mixing ratio.

\begin{tabular}{crr}
\hline $\begin{array}{c}\text { isentropic } \\
\text { surface }\end{array}$ & $\begin{array}{c}\text { temperature } \\
\text { anomaly }\end{array}$ & $\begin{array}{c}\text { rel. diff. of } \\
\text { saturation } \\
\text { mixing ratio }\end{array}$ \\
\hline $370 \mathrm{~K}$ & $-2.5 \mathrm{~K}$ & $-33 \%$ \\
& $-5.0 \mathrm{~K}$ & $-54 \%$ \\
& $-10.0 \mathrm{~K}$ & $-80 \%$ \\
\hline $355 \mathrm{~K}$ & $-2.5 \mathrm{~K}$ & $-30 \%$ \\
& $-5.0 \mathrm{~K}$ & $-50 \%$ \\
& $-10.0 \mathrm{~K}$ & $-76 \%$ \\
\hline
\end{tabular}

tical displacement of the isentropic surfaces, while the weak stability in the troposphere allows air parcels to move over larger distances. Consequently, in the TTL, the temperature variations in isentropic coordinates are larger than those in altitude coordinates; this is a very important point when we consider variations in water vapor or humidity.

Following the Clausius-Clapeyron relation, we can easily calculate the change in the saturation mixing ratio of water vapor according to that in the temperature in isentropic coordinates. Using the average profile as defined in Fig. 8, the relationship between the temperature anomaly $\left(T^{\prime}\right)$ and the relative difference in the saturation mixing ratio $\left(q_{s}^{\prime} / \bar{q}_{s}\right)$ at 355 and $370 \mathrm{~K}$ is presented in Table 1. Within this temperature range around the tropopause, changes in $T^{\prime}$ on the isentropic surface clearly affect $q_{s}^{\prime} / \bar{q}_{s}$, as shown in Table 1 . This result suggests that temperature disturbance plays an important role on the isentropic surface under saturated conditions; the decreases in water vapor of approximately $50 \%$ in the lower part of the TTL (around $355 \mathrm{~K}$ ) in Fig. $6 \mathrm{c}$ correspond approximately to the changes in the saturation mixing ratios in Table 1, owing to the adiabatic cooling of $5 \mathrm{~K}$.

The effect of large temperature variations in the TTL in isentropic coordinates was further investigated. Figure 9 shows the vertical distributions of the relative humidity with respect to ice. High values $(>100 \%)$ are sometimes seen around $345-360 \mathrm{~K}$ in the warm phase and around $360-380 \mathrm{~K}$ in the cold phase, indicating nearly saturated conditions. This is due to temperature disturbances corresponding to the combination of stationary and eastward-traveling cold anomalies over time, as discussed in Section 3. Thus, the decrease in the water vapor mixing ratio between 345 and $360 \mathrm{~K}$ from the cold to the warm phase could be understood

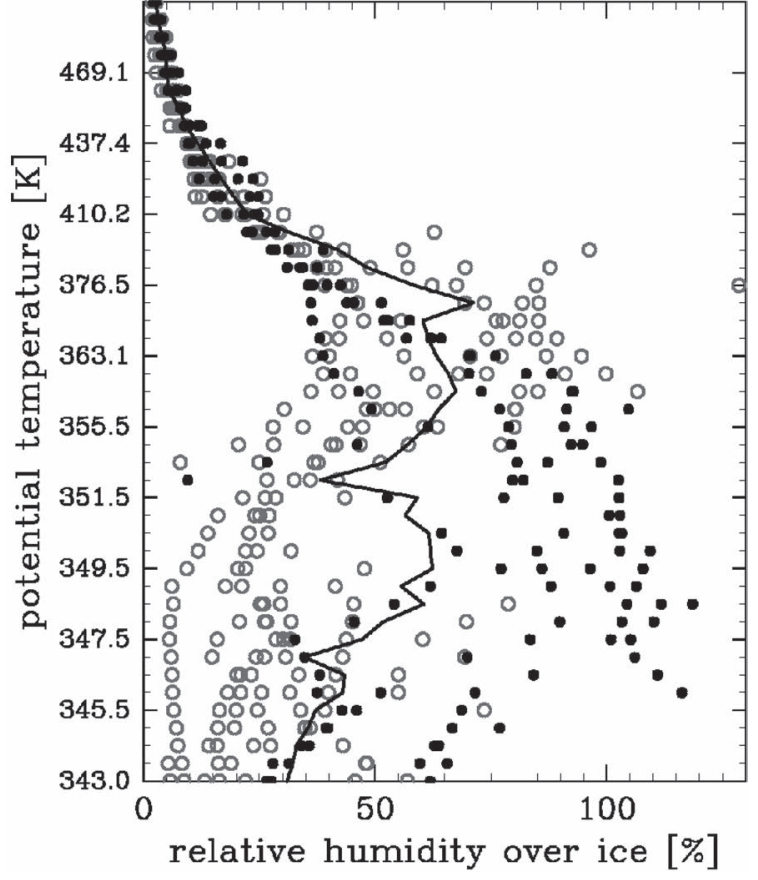

Fig. 9. Vertical profiles of relative humidity with respect to ice in isentropic coordinates during the cold phase (open circles) and warm phase (solid circles). The black line indicates the average for the observational period.

as its saturated condition during the warm phase around that height range.

On the other hand, the low values of relative humidity observed in the upper part of the TTL (around 370 $\mathrm{K}$ ) in the warm phase may be explained by vertical descents of isentropic surfaces. A decrease of approximately $20 \%$ in relative humidity around $370 \mathrm{~K}$ during the transition from the cold to the warm phase is consistent with $1 \mathrm{~K}$ of adiabatic warming (not shown). However, approximately $7 \mathrm{~K}$ of warming was actually observed around this level, which requires a much greater decrease in relative humidity and suggests the existence of a source of water vapor. Furthermore, the peak increases of approximately $80 \%$ and $130 \%$ in water vapor and ozone, respectively, near this level in isentropic coordinates, as shown in Fig. 6c, may be the upper limit of stratospheric air mixed by irreversible transport.

\section{Conclusions}

Water vapor and ozone profiles in the TTL were analyzed using water vapor and ozone sonde observations from the CEPEX campaign. Characteristic variations in 
water vapor, ozone, and temperature were found during the roughly two week observation period and within a spatial extent of approximately $2,700 \mathrm{~km}$. A clear distinction appeared between the first and latter halves of the observation period, which were characterized by cold and warm phases having large temperature disturbances near the cold point tropopause, respectively. However, the phase relationship in temperature was reversed around the bottom of the TTL. From the first half to the latter half of the period, even on the isentropic surface, increases in water vapor and ozone mixing ratios were found, with maximum peaks around the 360 to 370 $\mathrm{K}$ isentropes. In analyzing these signatures, we showed that it is important to view these quantities in isentropic coordinates rather than altitude coordinates.

The background temperature field along the observation points is characterized as a combination of stationary and eastward-traveling cold anomalies around the upper part of the TTL; the eastward signal may be related to a Kelvin wave. In association with the temperature variation, the water vapor mixing ratios are lower around the upper part of the TTL and higher around the lower part of the TTL in the cold phase than in the warm phase. Moreover, the ozone mixing ratios are lower around the TTL in the cold phase than in the warm phase. The vertical gradients of the water vapor and ozone profiles decreased at the transition from the cold to the warm phase near the CPT. In addition, enhancement of vertical shear of zonal wind during the transition between the two phases was observed.

Regarding the mechanism for increasing water vapor around $360-400 \mathrm{~K}$ and ozone around $350-400 \mathrm{~K}$ in isentropic coordinates, the turbulent mixing process associated with a breaking Kelvin wave is a possible interpretation as proposed by Fujiwara et al. (1998, 2003). The effect of mixing, not only on ozone but also on water vapor, is described in this paper. Nishi et al. (2007) recently showed that large-amplitude Kelvin waves are commonly seen from November to March, implying that a breaking event could occur as a consequence. This is consistent with the results of Flannaghan and Fueglistaler (2011), which suggested a mixing process in the TTL due to Kelvin waves.

Another interpretation of this simultaneous increase in water vapor and ozone is horizontal transport; however, contributions to the water vapor variation during horizontal transport (including adiabatic and diabatic) may be small near the central Pacific because the horizontal wind is weak (less than $5 \mathrm{~m} \mathrm{~s}^{-1}$ in Fig. 3). To understand the positive bias of the observed water vapor from in situ soundings (e.g., Hasebe et al. 2007), it may be necessary to include the influence of vertical mixing.
Gettelman et al. (2002) and Folkins and Martin (2005) showed that convective activity had a large effect even in the upper troposphere or around the bottom of the TTL, resulting in water vapor variations there. In this study, a relationship was also seen between organized convective activity and undulation of the isentropic surface because the downward displacement of isentropic surfaces in the lower part of the TTL may be affected by convective activity. These space-time variations in organized convection are expected to be closely related to the Madden-Julian Oscillation (Schwartz et al. 2008).

These results imply that the wave activities may change the water vapor and ozone budget in the TTL at time scales on the order of a week, as shown in recent observations by Fujiwara et al. (2009) and Suzuki et al. (2010b). Because of its quasi-conservative nature, ozone may be more suitable for detecting signals of turbulent mixing. Further observations and analysis of water vapor and ozone with high vertical resolution are necessary in order to understand these issues.

\section{Acknowledgements}

We thank Dr. H. Vömel and the CEPEX mission researchers for their data set. The authors acknowledge the European Centre for Medium-Range Weather Forecasts for providing the ERA-40 data and the NOAA Climate Diagnostics Center for providing the OLR data. The GFD-DENNOU Library was used to draw the figures. Finally, we thank two anonymous reviewers and the editor for their helpful and constructive reviews.

\section{References}

Boehm, M. T., and J. Verlinde, 2000: Stratospheric influence on upper tropospheric tropical cirrus. Geophys. Res. Lett., 27, 3209-3212.

Brewer, A. W., 1949: Evidence for a World Circulation Provided by the Measurements of Helium and Water Vapour Distribution in the Stratosphere. Quart. J. Roy. Meteor. Soc., 75, 351-363.

Chaboureau, J., J. Cammas, J. Duron, P. J. Mascart, N. M. Sitnikov, and H.-J. Voessing, 2007: A numerical study of tropical cross-tropopause transport by convective overshoots. Atmos. Chem. Phys., 7, 1731-1740.

Corti, T., B. P. Luo, Q. Fu, H. Vömel, and T. Peter, 2006: The impact of cirrus clouds on tropical troposphereto-stratosphere transport. Atmos. Chem. Phys., 6, 25392547.

Corti, T., B. P. Luo, M. de Reus, D. Brunner, F. Cairo, M. J. Mahoney, G. Martucci, R. Matthey, V. Mitev, F. H. dos Santos, C. Schiller, G. Shur, N. M. Sitnikov, N. Spelten, 
H. J. Voessing, S. Borrmann, and T. Peter, 2008: Unprecedented evidence for deep convection hydrating the tropical stratosphere. Geophys. Res. Lett., 35, L10810, doi:10.1029/2008GL033641.

Duchon, C., 1979: Lanczos filtering in one and two dimensions. J. Appl. Meteor., 18, 1016-1022.

Flannaghan, T. J., and S. Fueglistaler, 2011: Kelvin waves and shear-flow turbulent mixing in the TTL in (re-)analysis data. Geophys. Res. Lett., 38, L02801, doi:10.1029/2010GL045524.

Folkins, I., and R. V. Martin, 2005: The vertical structure of tropical convection and its impact on the budgets of water vapor and ozone. J. Atmos. Sci., 62, 1560-1573.

Folkins, I., M. Loewenstein, J. Podolske, S. J. Oltmans, and M. Proffitt, 1999: A barrier to vertical mixing at $14 \mathrm{~km}$ in the tropics: Evidence from ozonesondes and aircraft measurements. J. Geophys. Res., 104, 22095-22102.

Fueglistaler, S., and P. H. Haynes, 2005: Control of interannual and longer-term variability of stratospheric water vapor. J. Geophys. Res., 110, D24108, doi:10.1029/2005JD006019.

Fueglistaler, S., M. Bonazzola, P. H. Haynes, and T. Peter, 2005: Stratospheric water vapor predicted from the Lagrangian temperature history of air entering the stratosphere in the tropics. J. Geophys. Res., 110, D08107, doi:10.1029/2004JD005516.

Fueglistaler, S., A. E. Dessler, T. J. Dunkerton, I. Folkins, Q. Fu, and P. W. Mote, 2009: Tropical Tropopause Layer. Rev. Geophys., 47, RG1004, doi:10.1029/2008RG000267.

Fujiwara, M., and M. Takahashi, 2001: Role of the equatorial Kelvin wave in stratosphere-troposphere exchange in a general circulation model. J. Geophys. Res., 106, 22763-22780.

Fujiwara, M., K. Kita, and T. Ogawa, 1998: Stratospheretroposphere exchange of ozone associated with the equatorial Kelvin wave as observed with ozonesondes and rawinsondes. J. Geophys. Res., 103, 19173-19182.

Fujiwara, M., F. Hasebe, M. Shiotani, N. Nishi, H. Vömel, and S. J. Oltmans, 2001: Water vapor control at the tropopause by equatorial Kelvin waves observed over the Galapagos. Geophys. Res. Lett., 28, 3143-3146.

Fujiwara, M., M. K. Yamamoto, H. Hashiguchi, T. Horinouchi, and S. Fukao, 2003: Turbulence at the tropopause due to breaking Kelvin waves observed by the Equatorial Atmosphere Radar. Geophys. Res. Lett., 30, 1171, doi:10.1029/2002GL016278.

Fujiwara, M., S. Iwasaki, A. Shimizu, Y. Inai, M. Shiotani, F. Hasebe, I. Matsui, N. Sugimoto, H. Okamoto, N. Nishi, A. Hamada, T. Sakazaki, and K. Yoneyama, 2009: Cirrus observations in the tropical tropopause layer over the western Pacific. J. Geophys. Res., 114, D09304, doi:10.1029/2008JD011040.

Gettelman, A., M. L. Salby, and F. Sassi, 2002: Distribution and influence of convection in the tropical tropopause region. J. Geophys. Res., 107, 4080,
doi:10.1029/2001JD001048.

Hasebe, F., M. Fujiwara, N. Nishi, M. Shiotani, H. Voemel, S. Oltmans, H. Takashima, S. Saraspriya, N. Komala, and Y. Inai, 2007: In situ observations of dehydrated air parcels advected horizontally in the Tropical Tropopause Layer of the western Pacific. Atmos. Chem. Phys., 7, 803-813.

Hatsushika, H., and K. Yamazaki, 2003: Stratospheric drain over Indonesia and dehydration within the tropical tropopause layer diagnosed by air parcel trajectories. $J$. Geophys. Res., 108, 4610, doi:10.1029/2002JD002986.

Holton, J. R., and A. Gettelman, 2001: Horizontal transport and the dehydration of the stratosphere. Geophys. Res. Lett., 28, 2799-2802.

Holton, J. R., P. H. Haynes, M. E. Mcintyre, A. R. Douglass, R. B. Rood, and L. Pfister, 1995: StratosphereTroposphere Exchange. Rev. Geophys., 33, 403-439.

Jensen, E., and L. Pfister, 2004: Transport and freeze-drying in the tropical tropopause layer. J. Geophys. Res., 109, D02207, doi:10.1029/2003JD004022.

Kley, D., H. G. J. Smit, H. Vömel, H. Grassl, V. Ramanathan, P. J. Crutzen, S. Williams, J. Meywerk, and S. J. Oltmans, 1997: Tropospheric water-vapour and ozone cross-sections in a zonal plane over the Central Equatorial Pacific Ocean. Quart. J. Roy. Meteor. Soc., 123, 2009-2040.

Nishi, N., J. Suzuki, A. Hamada, and M. Shiotani, 2007: Rapid Transitions in Zonal Wind Around the Tropical Tropopause and their Relation to the Amplified Equatorial Kelvin Waves. SOLA, 3, 13-16, doi:10.2151/sola.2007-004.

Notholt, J., B. P. Luo, S. Fueglistaler, D. Weisenstein, M. Rex, M. G. Lawrence, H. Bingemer, I. Wohltmann, T. Corti, T. Warneke, R. von Kuhlmann, and T. Peter, 2005: Influence of tropospheric SO2 emissions on particle formation and the stratospheric humidity. Geophys. Res. Lett., 32, L07810, doi:10.1029/2004GL022159.

Schwartz, M. J., D. E. Waliser, B. Tian, D. L. Wu, J. H. Jiang, and W. G. Read, 2008: Characterization of MJO-related upper tropospheric hydrological processes using MLS. Geophys. Res. Lett., 35, L08812, doi:10.1029/2008GL033675.

Sherwood, S., 2002: A microphysical connection among biomass burning, cumulus clouds, and stratospheric moisture. Science, 295, 1272-1275.

Straub, K. H., and G. N. Kiladis, 2002: Observations of a convectively coupled Kelvin wave in the eastern Pacific ITCZ. J. Atmos. Sci., 59, 30-53.

Suzuki, J., M. Shiotani, and N. Nishi, 2010a: Lifetime and longitudinal variability of equatorial Kelvin waves around the tropical tropopause region. J. Geophys. Res., 115, D03103, doi:10.1029/2009JD012261.

Suzuki, J., M. Fujiwara, A. Hamada, Y. Inai, J. Yamaguchi, R. Shirooka, F. Hasebe, and T. Takano, 2010b: Cloud-Top Height Variability Associated with Equatorial Kelvin Waves in the Tropical Tropopause Layer during the 
Mirai Indian Ocean cruise for the Study of the MJOConvection Onset (MISMO) Campaign. SOLA, 6, 97100, doi:10.2151/sola.2010-025.

Tsuda, T., Y. Murayama, H. Wiryosumarto, S. W. B. Harijono, and S. Kato, 1994: Radiosonde Observations of Equatorial Atmosphere Dynamics Over Indonesia. 1. Equatorial Waves and Diurnal Tides. J. Geophys. Res., 99, 10491-10505.

Vömel, H., and K. Diaz, 2010: Ozone sonde cell current measurements and implications for observations of nearzero ozone concentrations in the tropical upper troposphere. Atmos. Meas. Tech., 3, 495-505.
Vömel, H., S. J. Oltmans, D. Kley, and P. J. Crutzen, 1995: New Evidence for the Stratospheric Dehydration Mechanism in the Equatorial Pacific. Geophys. Res. Lett., 22, 3235-3238.

Wheeler, M., and G. N. Kiladis, 1999: Convectively coupled equatorial waves: Analysis of clouds and temperature in the wavenumber-frequency domain. J. Atmos. Sci., 56, 374-399.

Wheeler, M., G. N. Kiladis, and P. J. Webster, 2000: Largescale dynamical fields associated with convectively coupled equatorial waves. J. Atmos. Sci., 57, 613-640. 